University of Wollongong

Research Online

Faculty of Engineering and Information

Faculty of Engineering and Information

Sciences - Papers: Part A

Sciences

$1-1-2015$

\title{
Analysis of thin strip profile by work roll crossing and shifting in asymmetrical cold rolling
}

Abdulrahman Aljabri

University of Wollongong, ada507@uowmail.edu.au

Zhengyi Jiang

University of Wollongong, jiang@uow.edu.au

Dongbin Wei

University of Technology, Sydney, dwei@uow.edu.au

Follow this and additional works at: https://ro.uow.edu.au/eispapers

Part of the Engineering Commons, and the Science and Technology Studies Commons

Research Online is the open access institutional repository for the University of Wollongong. For further information contact the UOW Library: research-pubs@uow.edu.au 


\title{
Analysis of thin strip profile by work roll crossing and shifting in asymmetrical cold rolling
}

\begin{abstract}
In order to analyze the effects of cold rolling parameters such as the crossing angle and axial shifting value of work rolls on the strip profile, extensive tests were carried out on a 4-high rolling mill equipped with a work roll crossing and shifting system. The results show that the strip profile is nearly flat under asymmetrical rolling. The rolling force was also analyzed in detail by changing the crossing angle and axial shifting value of work rolls.
\end{abstract}

\section{Keywords}

profile, work, shifting, roll, crossing, asymmetrical, rolling, cold, analysis, thin, strip

Disciplines

Engineering | Science and Technology Studies

\section{Publication Details}

Aljabri, A., Jiang, Z. \& Wei, D. (2015). Analysis of thin strip profile by work roll crossing and shifting in asymmetrical cold rolling. International Journal of Modern Physics B, 29 (10-11), 1540032-1-1540032-7. 


\title{
Analysis of Thin strip Profile by Work roll Crossing and Shifting in Asymmetrical Cold rolling
}

\author{
ABDULRAHMAN ALJABRI and ZHENGYI JIANG
}

School of Mechanical, Materials and Mechatronic Engineering, University of Wollongong, Wollongong NSW 2522, Australia ada507@uowmail.edu and jiang@uow.edu.au

DONGBIN WEI

School of Electrical, Mechanical, and Mechatronic Systems, University of Technology Sydney, Sydney NSW 2001, Australia

dwei@uow.edu.au

\begin{abstract}
In order to analyse the effects of cold rolling parameters such as the crossing angle and axial shifting value of work rolls on the strip profile, an extensive tests were carried out on a 4-high rolling mill equipped with a work roll crossing and shifting system. The results show that the strip profile is nearly flat under asymmetrical rolling. The rolling force was also analyzed in details by changing the crossing angle and axial shifting value of work rolls.
\end{abstract}

Keywords: Asymmetrical rolling; work roll crossing; work roll shifting; strip profile; thin strip; cold rolling

\section{Introduction}

Rolling of flat metal products is a complex process where the quality of the product is influenced by various factors like incoming material, mechanical and electrical equipment, lubrication and control strategies. One of the critical feature for assessing the quality of the rolled metal strip is the cross-sectional strip thickness profile ${ }^{1}$. The profile of thin strip must be controlled during rolling to maintain the dimensional quality that customers require. During rolling the profile is controlled by an advanced shape control rolling mill where the work rolls simultaneously cross and shift during asymmetrical rolling; this method is one that used to control the strip profile during rolling. Researchers have developed a variety of advanced control rolling mills ${ }^{2-5}$ to improve the shape and profile of strip, in one of which the strip profile is controlled by varying the shape of the gap between the work rolls, this is called the roll gap profile ${ }^{4}$. Controlling the roll gap profile is possible on mills equipped with work roll crossing, and in the combination of roll axial shifting and asymmetrical rolling. A roll crossing mill controls the thickness across the strip while roll shifting improves the roll bending which in turn reduces the edge drop, while maintaining uniform wear and the thermal crown on the work rolls ${ }^{6}$. At the same time, asymmetrical rolling can dramatically decrease the rolling force due to the cross shear region between the backward slip zone and the forward slip zone, as shown in Fig. 1(a), and it can also reduce the edge drop while the crown on strip becomes smaller. Researchers have studied how the rolling parameters affect the shape and profile of rolled strip ${ }^{7-9}$. The ability of a work roll crossing and shifting mill to control the crown and its subsequent effect on rolling mechanics are also discussed ${ }^{10-13}$.

The system of asymmetrical cold rolling with work roll crossing shown in Fig. 1 is a metal forming process where different peripheral velocities $\left(\mathrm{V}_{1}\right.$ and $\left.\mathrm{V}_{2}\right)$ exist between the two rolls due to variations in their diameters $\left(\mathrm{R}_{1}\right.$ and $\left.\mathrm{R}_{2}\right)$, and where both work rolls are in contact under a crossed and shifting state, as shown in Fig. 1(a $\& b)$. This combined multiple shape control system is a highly efficient method of controlling the shape and profile of cold rolled strip.

†Corresponding author 


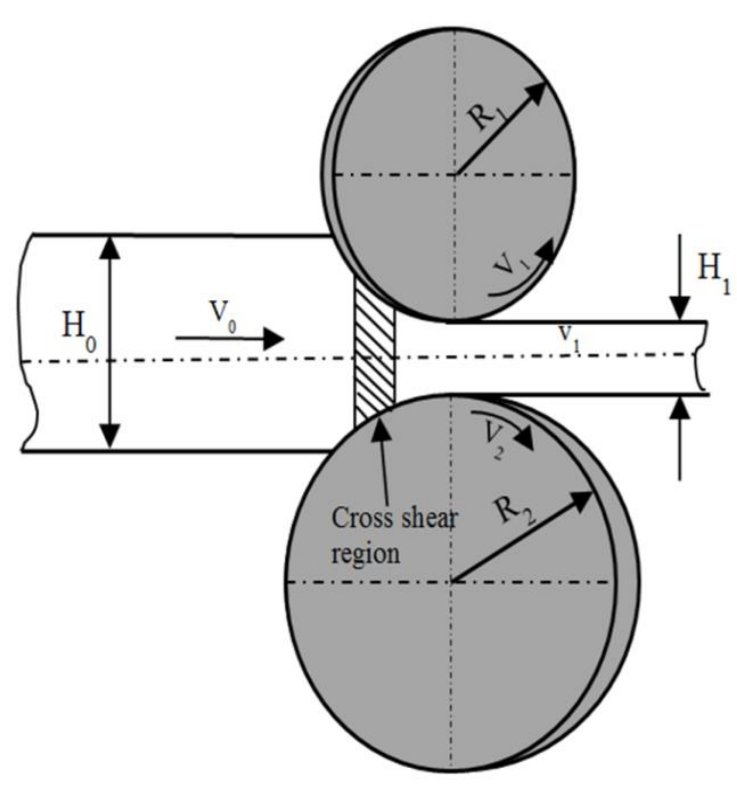

(a)

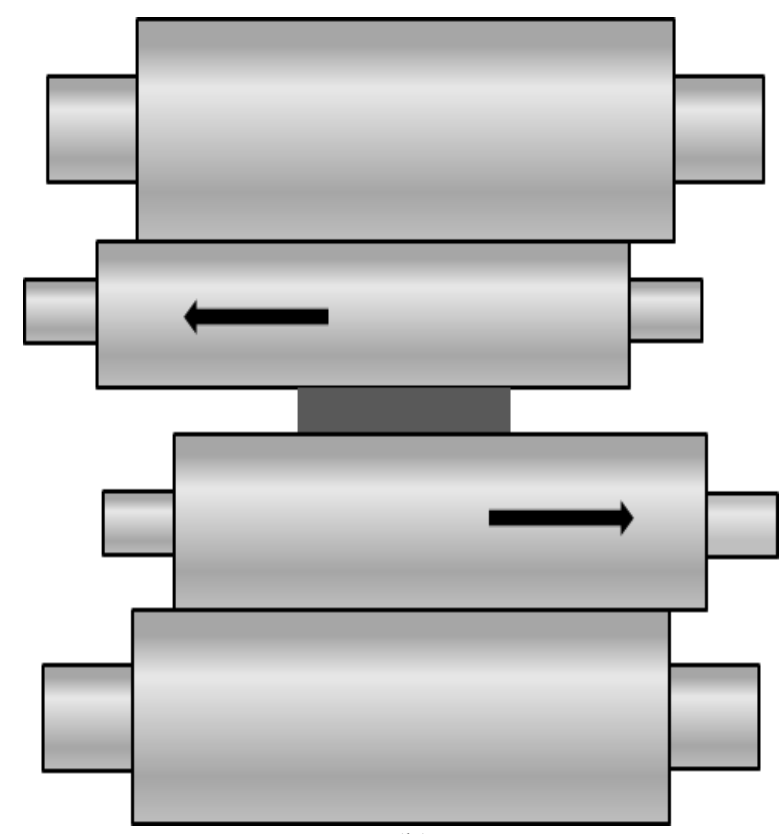

(b)

Fig. 1. Schematic of rolling process (a) asymmetrical rolling with work rolls crossing, (b) with work rolls shifting

This study aims to present our contribution towards an illumination of the thickness accuracy control in thin strip cold rolling by experimental approach. The experiments have been carried out on a 4-high Hille 100 rolling mill revamped for the purpose of research with a work roll crossing and shifting system. The confirmatory tests were performed by modifying an ordinary cold rolling mill to work roll crossing and shifting system. The specification for the test mill is given in Table 1.

Table 1. Specification for the 4-high asymmetrical rolling

\begin{tabular}{ll}
\hline Mill system & Work roll crossing and shifting \\
Cross angle & $0^{\circ}, 0.5^{\circ}, 1.0^{\circ}$ \\
Shifting value & $0-16 \mathrm{~mm}$ \\
Upper work roll & Diameter $=63 \mathrm{~mm}$, length $=250 \mathrm{~mm}$ \\
Down work roll & Diameter $=76 \mathrm{~mm}$, length $=250 \mathrm{~mm}$ \\
Backup roll & Diameter $=228 \mathrm{~mm}$, length $=250 \mathrm{~mm}$ \\
\hline
\end{tabular}

\section{Results and discussion}

The strip shape quality control is one of the key issues in rolling technology and is achieved by controlling the variations of the strip thickness (strip profile) during rolling. In this paper, the factor of strip profile control in asymmetrical and symmetrical rolling is discussed in details.

\subsection{Effects of rolling parameters on strip shape quality}

Figs.2-3 show the exit strip profiles and the rolling force under different work roll crossing angle. The exit strip profile in asymmetrical rolling and symmetrical rolling (standard 4-high) is shown in Fig. 1. It can be seen that if the symmetrical rolling process with crossing angle is carried out, the edge buckle is observed. However, the strip profile is roughly flat under asymmetrical rolling with increasing the crossing angle. This is due to the existing of the cross shear region in the roll bite, which makes the rolling force reduce significantly as shown in Fig. 2, and the crossing angle changes the roll gap distribution that leads to the strip thickness distribution in the width direction be constant. 


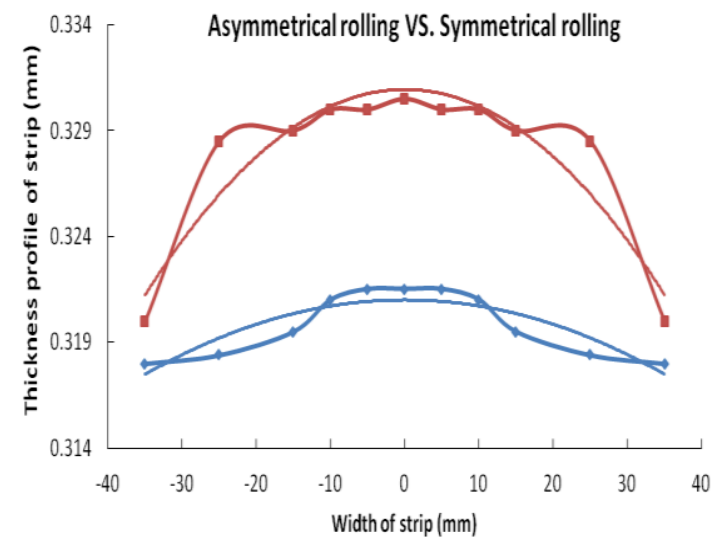

$\longrightarrow$ Asymmetrical rolling -0.5 crossing angle $=$ Symmetrical rolling -0.5 crossing angle

(a)

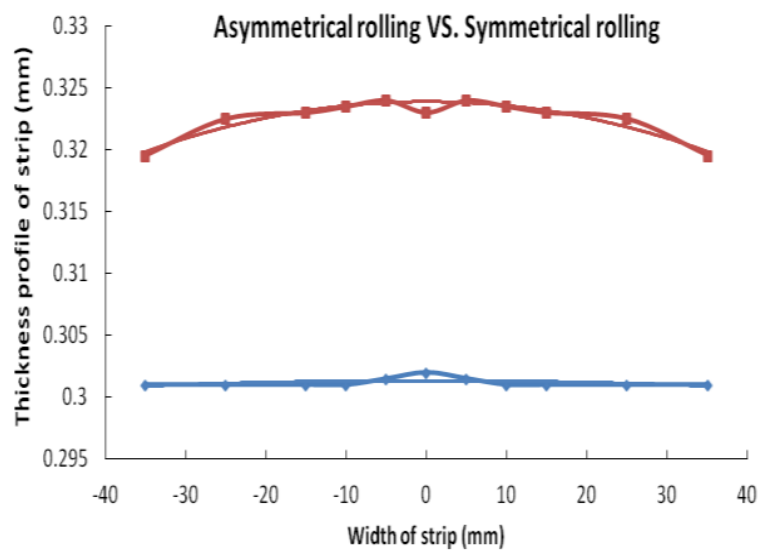

$\mp$ Asymmetrical rolling -1.0 crossing angle $=$ Symmetrical rolling -1.0 crossing angle

(b)

Fig. 2. Strip profile in asymmetrical and symmetrical rolling (a) $0.5^{\circ}$ crossing angle and (b) $1.0^{\circ}$ crossing angle

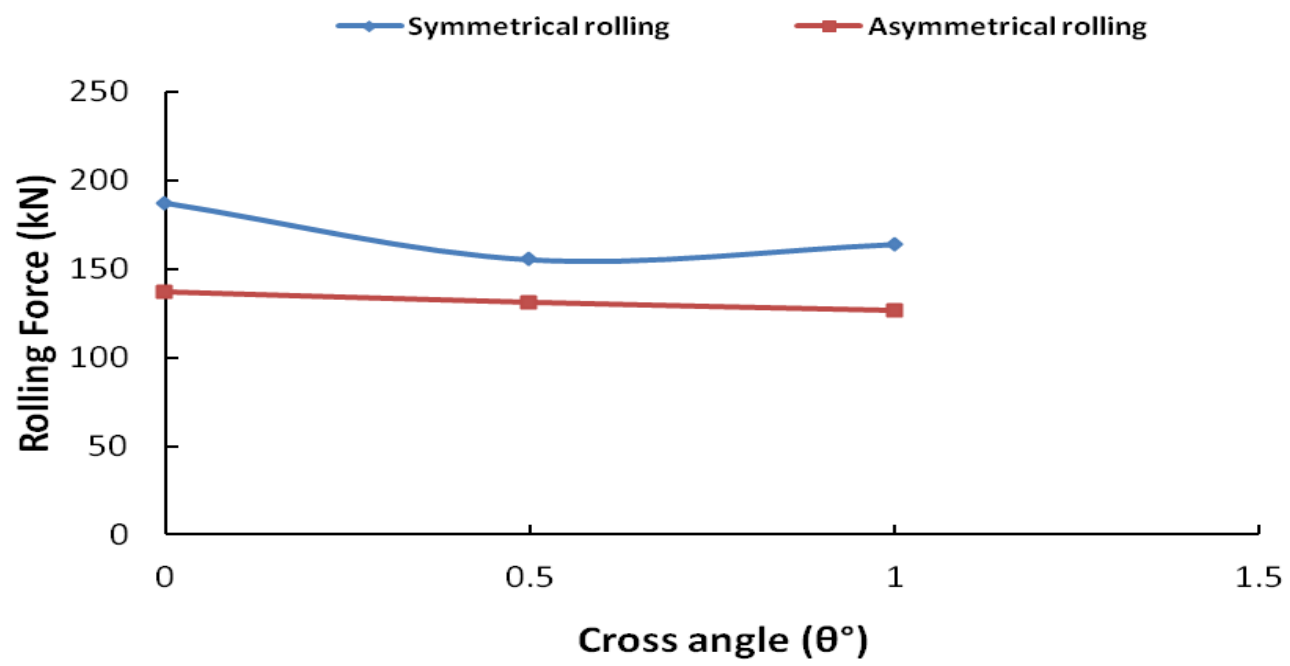

Fig. 3 .Total rolling force in asymmetrical and symmetrical rolling under different work roll crossing angle

\subsection{Influence of crossing angle on the strip thickness distribution}

Figs. 4-5 show the effects of the work roll crossing angle with different thickness reductions under asymmetrical rolling. It can be seen that the strip thickness profile along the width direction improved significantly as the cross angle increases for asymmetrical rolling with different thickness reductions, but more improved with lower reduction. In addition, lubrication contributed to an improved strip profile. The results show a better-quality strip shape with lubricated sample as shown in Fig. 4. This proves that the work roll crossing system has a capability to adjust the roll gape profile causing the roll gap distribution to be uniformed. Simultaneously, asymmetrical rolling makes the rolling force decrease dramatically in present of lubrication, so the strip profile is significantly improved. 


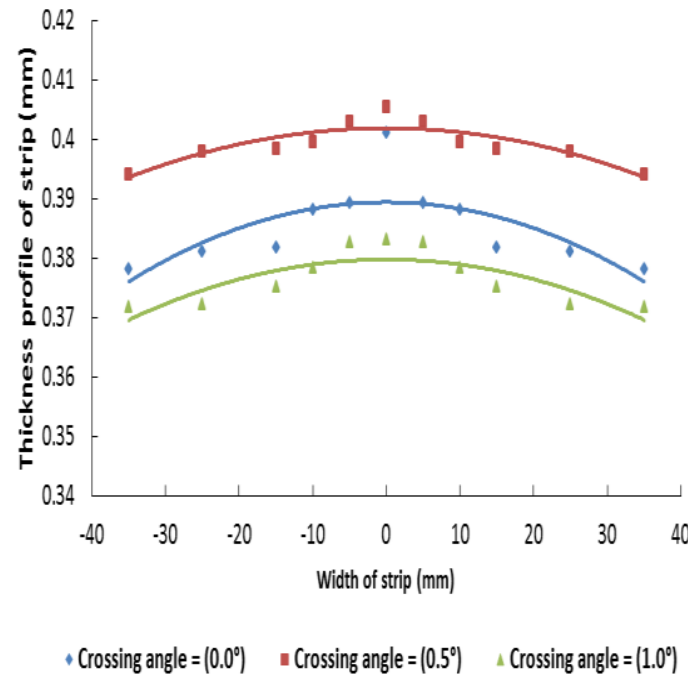

(a)

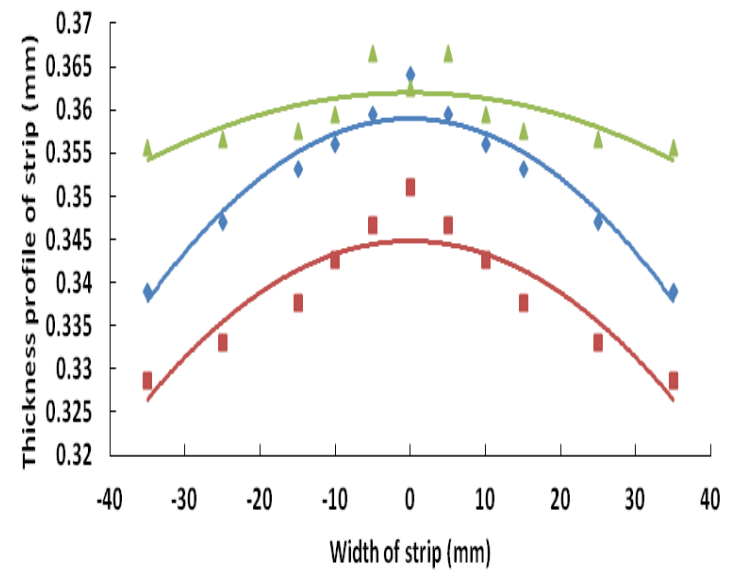

- Crossing angle $=\left(0.0^{\circ}\right) \quad$ Crossing angle $=\left(0.5^{\circ}\right) \Delta$ Crossing angle $=\left(1.0^{\circ}\right)$

(b)

Fig. 4 Exit strip profile for different crossing angle in a symmetrical rolling under unlubricated rolling process. (a) $20 \%$ thickness reduction and (b) $30 \%$ thickness reduction

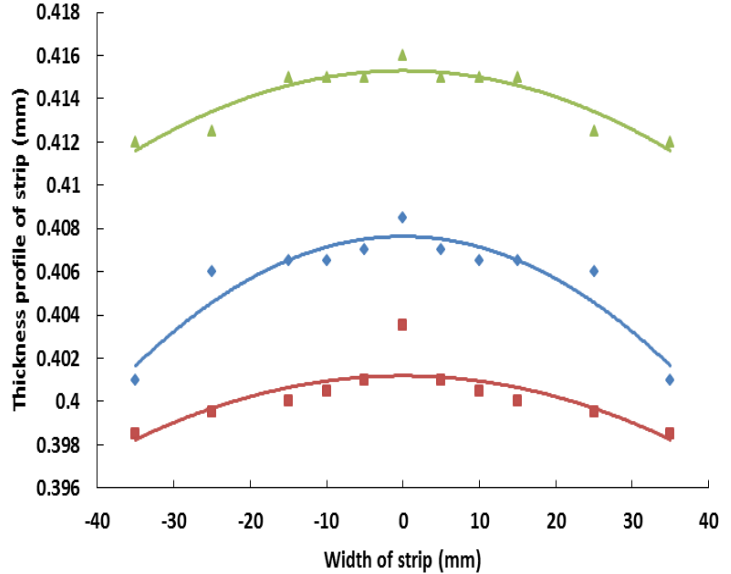

- Crossing angle $=\left(0.0^{\circ}\right) \quad$ Crossing angle $=\left(0.5^{\circ}\right) \quad \triangle$ Crossing angle $=\left(1.0^{\circ}\right)$

(a)

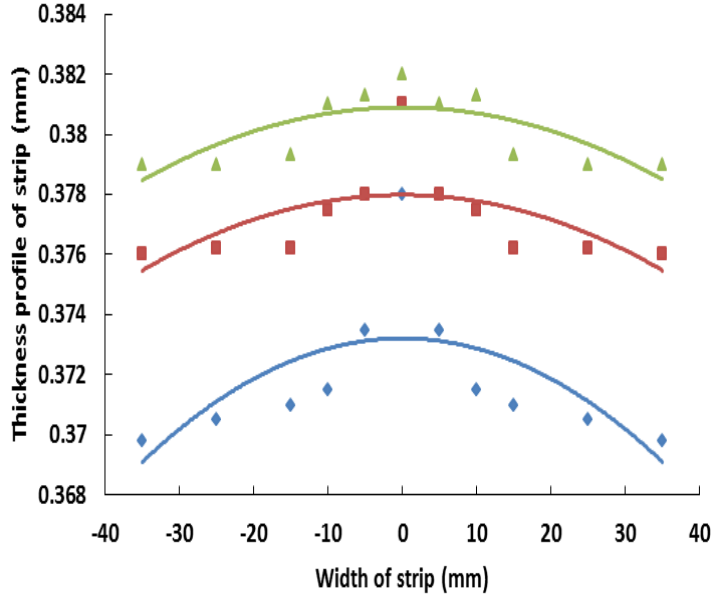

- Crossing angle $=\left(0.0^{\circ}\right) \quad$ Crossing angle $=\left(0.5^{\circ}\right) \triangle$ Crossing angle $=\left(1.0^{\circ}\right)$

(b)

Fig. 5 Exit strip profile for different crossing angle in a symmetrical rolling under lubricated rolling process. (a) $20 \%$ thickness reduction and (b) $30 \%$ thickness reduction

\subsection{Influence of crossing angle and shifting of work rolls on the strip thickness distribution}

It was found that as the work roll crossing and shifting rolling mill used as a multiple shape control system provides high efficiency profile control devices. The influence of the work rolls crossing and shifting on strip profile under asymmetrical rolling condition was analyzed as shown in Fig. 6. It can be seen that the strip profile changes toward flat shape when changing the work roll axial shifting value, and the strip profile becomes more improvement when the crossing angle increases with different reductions. This could be a result of modifying the roll gap profile by crossing angle and simultaneously the roll bending improves as the shift amount of roll stroke increases.

Fig. 7 shows the metric of crown and edge drop were used to evaluate the strip profile. The strip crown $\mathrm{C}_{5}$ was defined as the variation value between the thickness at the strip centre and the thickness at a $5 \mathrm{~mm}$ distance from the edge, and the edge drop $C_{e}$ was defined as the variation value between the thickness at $35 \mathrm{~mm}$ distance from the strip edge, and the thickness at the $10 \mathrm{~mm}$ distance from the strip edge. It can be clearly seen that both $\mathrm{C}_{5}$ and $\mathrm{C}_{\mathrm{e}}$ decrease with an increase of the roll crossing angle and shifting value, which was attributed to the fact 
that the transverse flow of the metal was controlled with crossing angle, and the roll shifting controls the strip shape and crown by improving the bending roll effect, to reduce the edge drop of the strip.

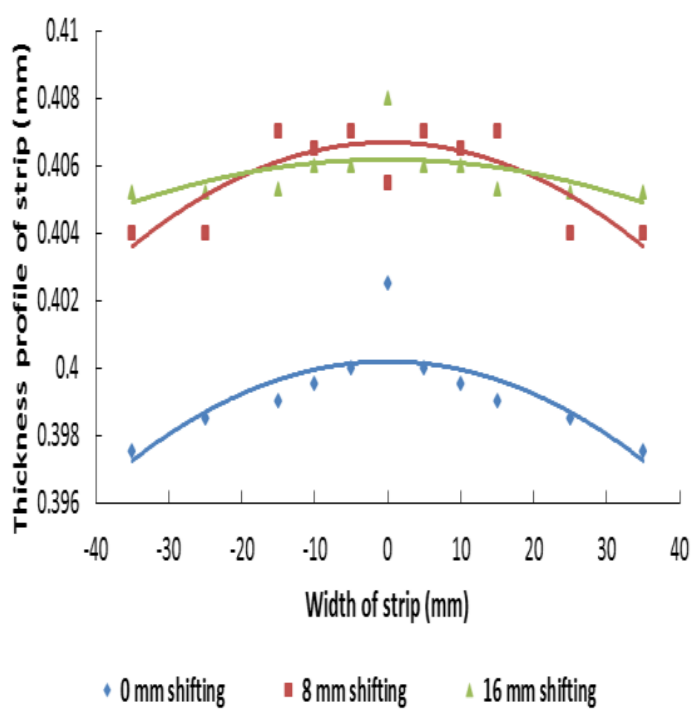

(a)

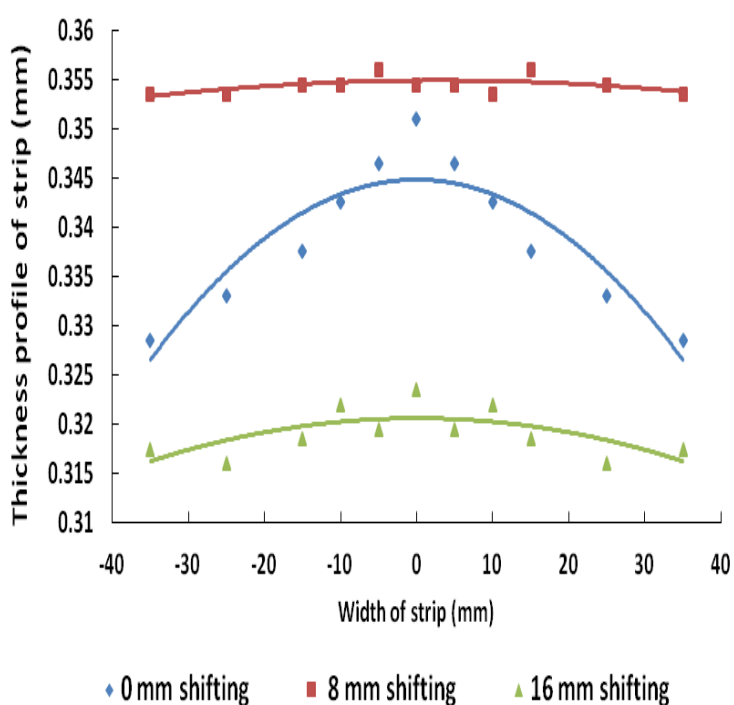

(b)

Fig. 6 Strip profile for crossing angle and different shifting values in a symmetrical rolling. (a) $20 \%$ thickness reduction and (b) $30 \%$ thickness reduction

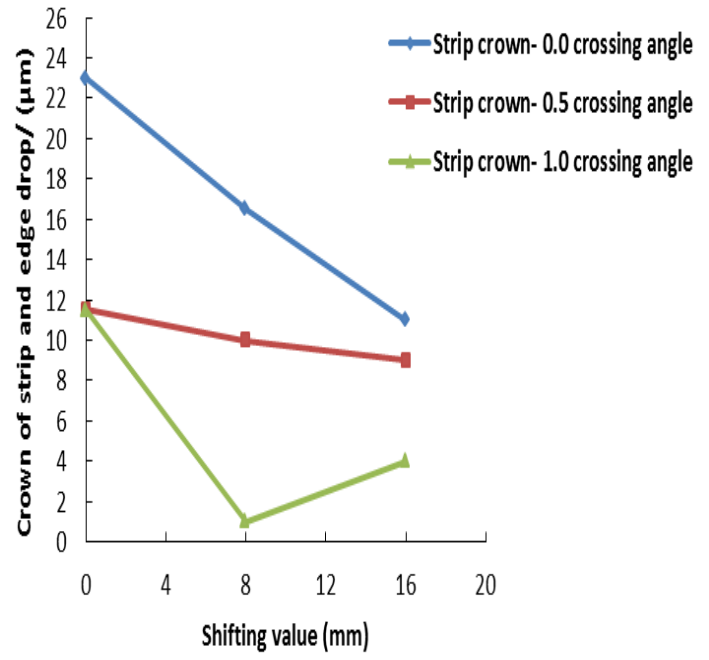

(a)

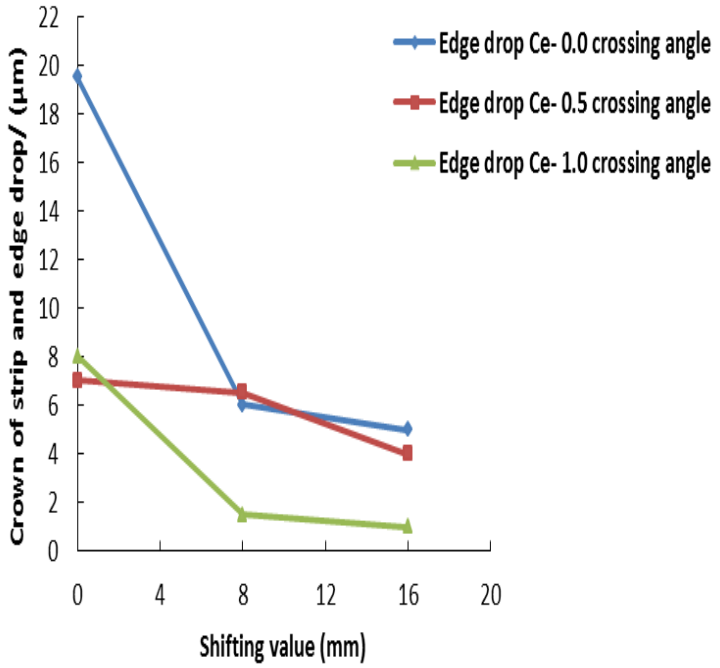

(b)

Fig. 7 Strip crown $\mathrm{C}_{5}$ (a) and edge drop $\mathrm{C}_{\mathrm{e}}$ (b) for different crossing angles and shifting values in a symmetrical rolling.

\section{Conclusion}

The effect of the rolling parameters: work roll crossing, work roll shifting, asymmetrical rolling with different thickness reductions on strip profile during thin strip rolling were studied. The exit strip profile for cold rolling of thin strip was systematically estimated considering the work roll crossing, axial work roll shifting and the combination of the work rolls crossing and shifting using a 4-high asymmetrical rolling mill. Experimental results show that the work roll crossing angle provides improved strip shape by modifying the roll gap distribution caused by load variation. The strip profile is nearly flat under asymmetrical rolling with an increase of crossing angle and axial shifting value with lower reduction. Additionally, asymmetrical rolling provides improved efficiencies by reducing the rolling forces. By reducing the rolling force, roll wear and subsequently 
maintenance costs can be reduced. The practical application has demonstrated that the combination of the work rolls crossing and shifting during asymmetrical rolling can effectively improve the strip profile.

\section{Acknowledgments}

The authors gratefully acknowledge the Australian Research Council (ARC) funding support for this research. The authors would also thank Mr. Joe Abbott's assistance in the experimental work. The first author is grateful to the Ministry of Higher Education under King Abdullah Scholarships Program for the financial support towards his $\mathrm{PhD}$ study.

\section{References}

1. A.S. Malik and R.V. Grandhi, Recent developments in strip-profile calculation, in Flat-Rolled Steel Processes Advanced Technologies, V.B. Ginzburg, Editor. 2009. p. 392-339.

2. N. Kiyoshi, et al., High reduction rolling technology on pair cross mill. Nippon Steel Technology Report No.75, 1997: p. 9-23.

3. V.B. Ginzburg and M. Azzam, Selection of optimum strip profile and flatness technology for rolling mills. Iron And Steel Engineering, 1997. 74: p. 30-37.

4. V.B. Ginzburg, Roll crossing and shifting system. 1997, Danieli United, A Division of Danieli Corporation; intenational Rolling Mill Consultants, Inc. : USA. p. 1-18.

5. Y. Miyai, R. Shimizu, and T. Kawasaki, Modernization and operation of NKK's Keihin hot strip mill. Iron and Steel Engineer, 1991. Nov: p. 35-40.

6. Y. Qiulin and F. Kuan-Chen, Method for controlling axial shifting rolls. 1995, The University of Toledo: Canda. p. 1-17.

7. Z.Y. Jiang, et al., strip shape analysis of asymmetrical cold rolling of thin strip. Advanced Material Research, 2010. 97101: p. 81-84

8. Z.Y. Jiang, D.B. Wei, and A.K. Tieu, Analysis of cold rolling of ultra thin strip. Journal of Materials Processing Technology, 2009. 209: p. 4584-4589.

9. Z.Y. Jiang, H.T. Zhu, and A.K. Tieu, Analysis of asymmetrical rolling for cold rolling due to roll edge contact. Key Engineering Materials, 2004. 274-276: p. 715-720.

10. S. Omori, et al., Analysis of rolling load generated by pair crossed rolling mill. Ironmaking \& Steelmaking, 2004. 31: p. 71-80.

11. M. Kitahama, et al., Profile Control of hot rolled strip by work roll shifting ( $K$-WRS) mill. Iron and Steel Engineering, 1987: p. 34-42.

12. A. Aljabri, et al., Thin strip profile control capability of roll crossing and shifting in cold rolling mill. Material Science Forum, 2013. 773-774: p. 70-78.

13. A. Aljabri, et al. Modeling of Thin Strip Profile during Cold Rolling on Roll Crossing and Shifting Mill. in PRICM: 8 Pacific Rim International Congress on Advanced Materials and Processing. Waikoloa, Hawaii, USA, (John Wiley \& Sons, Inc., 2013). 